\title{
Improving Power Quality in a Multi bus Multi Feeder System Using MC-UPQC
}

\author{
Mr.S.Baba Shareef*, Mr.C.Ganesh**, Mrs.S.Sarada*** \\ (PG Student, EEE Department, Annamacharya institute of Technology and sciences, Rajampeta) \\ (Associate professor, EEE Department Annamacharya institute of Technology and sciences, Rajampeta) \\ (Associate Professor, EEE Department Annamacharya institute of Technology and sciences, Rajampta)
}

\begin{abstract}
This paper presents a new Unified Power-Quality Conditioning System (MC-UPQC), capable of simultaneous compensation for voltage and current in multi-bus/multi-feeder systems. By using one shunt Voltage-Source Converter (VSC) and two or more series VSCs the configuration is made. The system can be applied to adjacent feeders to compensate for supply-voltage and load current imperfections on the main feeder and full compensation of supply voltage imperfections on the other feeders. The configuration will be designed as all converters are connected back to back on the dc side and share a common dc-link capacitor. The system is also capable of compensating for interruptions without the need for a battery storage system and consequently without storage capacity limitations. By the simulation the performance of MC-UPQC as well as the adopted control algorithm will be illustrated.
\end{abstract}

Index-terms: Voltage-Source Converter (VSC), Interline Power Flow Controller (IPFC), Unified PowerQuality Conditioning System (UPQC),

\section{Introduction}

When the power flows of two lines starting in one substation need to be controlled, an Interline Power Flow Controller (IPFC) can be used. An IPFC consists of two series VSCs whose de capacitors are coupled. This allows active power to circulate between the VSCs. With this configuration, two lines can be controlled simultaneously to optimize the network utilization. The GUPFC combines three or more shunt and series converters. It extends the concept of voltage and power-flow control beyond what is achievable with the known two-converter UPFC. The simplest GUPFC consists of three converters-one connected in shunt and the other two in series with two transmission lines in a substation. The basic GUPFC can control total five power system quantities, such as a bus

as well. By using GUPFC devices, the transfer capability of transmission lines can be increased significantly.

Furthermore, by using the multiline-management capability of the GUPFC, active power flow on lines cannot only be increased, but also be decreased with respect to operating and market transaction requirements. In general, the GUPFC can be used to increase the transfer capability and relieve congestions in a flexible way. This concept can be extended to design multiconverter configurations for PQ improvement in adjacent feeders. For example, the interline unified power-quality conditioner (IUPQC), which is the extension of the IPFC concept at the distribution level, has been proposed in the IUPQC consists of one series and one shunt converter. It is connected between two feeders to regulate the bus voltage of one of the feeders, while regulating the voltage across a sensitive load in the other feeder. In this configuration, the voltage regulation in one of the feeders is performed by the shunt-VSC. However, since the source impedance is very low, a high amount of current would be needed to boost the bus voltage in case of a voltage sag/swell which is not feasible. It also has low dynamic performance because the dc-link capacitor voltage is not regulated.

In this paper, a new configuration of a UPQC called the multiconverter unified power-quality conditioner (MC-UPQC) is presented. The system is extended by adding a series-VSC in an adjacent feeder. The proposed topology can be used for simultaneous compensation of voltage and current imperfections in both feeders by sharing power compensation capabilities between two adjacent feeders which are not connected. The system is also capable of compensating for interruptions without the need for a battery storage system and consequently without storage capacity limitations. 


\section{A. Circuit Configuration}

\section{Proposed Mc-Upqc System}

The single-line diagram of a distribution system with an MC-UPQC is shown in Fig. 1.

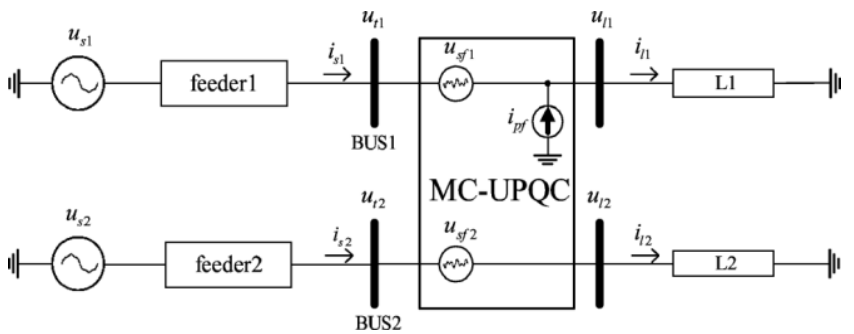

Fig.1 Single-line diagram of a distribution system with an MC-UPQC.

As shown in this fig.1. two feeders connected to two different substations supply the loads $\mathrm{L}_{1}$ and $\mathrm{L}_{2}$. The MC-UPQC is connected to two buses BUS ${ }_{1}$ and $\mathrm{BUS}_{2}$ with voltages of $\mathrm{u}_{\mathrm{t} 1}$ and ut2, respectively. The shunt part of the MC-UPQC is also connected to load $L_{1}$ with a current of $i_{11}$. Supply voltages are denoted by $u_{s 1}$ and $u_{s 2}$ while load voltages are $u_{11}$ and $u_{12}$ finally, feeder currents are denoted by $i_{s 1}$ and $i_{s 2}$ load currents are $i_{11}$ and $i_{12}$ Bus voltages $\mathrm{u}_{\mathrm{t} 1}$ and $\mathrm{u}_{\mathrm{t} 2}$ are distorted and may be subjected to sag/swell. The load $\mathrm{L}_{1}$ is a nonlinear/sensitive load which needs a pure sinusoidal voltage for proper operation while its current is non-sinusoidal and contains harmonics. The load $\mathrm{L}_{2}$ is a sensitive/critical load which needs a purely sinusoidal voltage and must be fully protected against distortion, sag/swell, and interruption. These types of loads primarily include production industries and critical service providers, such as medical centers, airports, or broadcasting centers where voltage interruption can result in severe economical losses or human damages.

\section{B. MC-UPQC Structure}

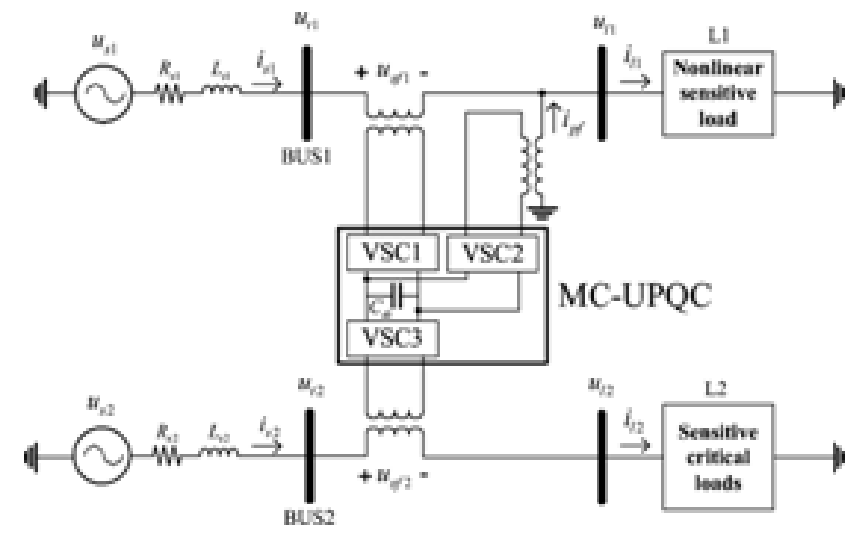

Fig.2 Typical MC-UPQC used in a distribution system

The internal structure of the MC-UPQC is shown in Fig.2.

It consists of three VSCs $\left(\mathrm{VSC}_{1}, \mathrm{VSC}_{2}\right.$, and $\mathrm{VSC}_{3}$ ) which are connected back to back through a common dc-link capacitor. In the proposed configuration, $\mathrm{VSC}_{1}$ is connected in series with $\mathrm{BUS}_{1}$ and $\mathrm{VSC}_{2}$ is connected in parallel with load $\mathrm{L}_{1}$ at the end of Feeder ${ }_{1}$. VSC ${ }_{3}$ is connected in series with $\mathrm{BUS}_{2}$ at the Feeder end. Each of the three VSCs in Fig. 3 is realized by a three-phase converter with a commutation reactor and high-pass output filter as shown in Fig.3.

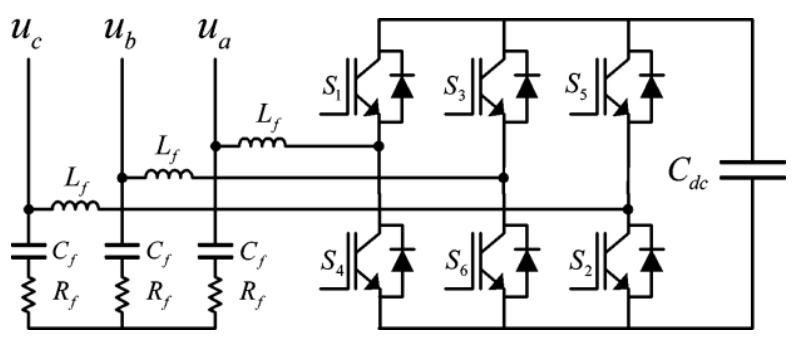

Fig 3 Schematic structure of a VSC 
The commutation reactor $\left(\mathrm{L}_{\mathrm{f}}\right)$ and high- pass output filter $\left(\mathrm{R}_{\mathrm{f}}, \mathrm{C}_{\mathrm{f}}\right)$ connected to prevent the flow of switching harmonics into the power supply. As shown in Fig, all converters are supplied from a common dclink capacitor and connected to the distribution system through a transformer. Secondary (distribution) sides of the series-connected transformers are directly connected in series with $\mathrm{BUS}_{1}$ and $\mathrm{BUS}_{2}$, and the secondary (distribution) side of the shunt-connected transformer is connected in parallel with load $\mathrm{L}_{1}$.

\section{The aims of the MC-UPQC shown in Fig are:}

1) To regulate the load voltage $\left(\mathrm{u}_{11}\right)$ against sag/swell and disturbances in the system to protect the nonlinear/sensitive load $\mathrm{L}_{1}$;

2) To regulate the load voltage $u_{12}$ against sag/swell, interruption, and disturbances in the system to protect the sensitive/ critical load $\mathrm{L}_{2}$;

3) To compensate for the reactive and harmonic components of nonlinear load current $\left(i_{11}\right)$.

In order to achieve these goals, series VSCs (i.e., $\mathrm{VSC}_{1}$ and $\mathrm{VSC}_{3}$ ) operate as voltage controllers while the shunt VSC (i.e., $\mathrm{VSC}_{2}$ ) operates as a current controller.

\section{Control Strategy}

As shown in Fig.4, the MC-UPQC consists of two series VSCs and one shunt VSC which are controlled independently. The switching control strategy for series VSCs and the shunt VSC are selected to be sinusoidal pulse width-modulation (SPWM) voltage control and hysteresis current control, respectively. Details of the control algorithm, which are based on the $\mathrm{d}-\mathrm{q}$ method, will be discussed later. Shunt-VSC: Functions of the shunt-VSC are:

1) To compensate for the reactive component of load $\mathrm{L}_{1}$ current;

2) To compensate for the harmonic components of load $\mathrm{L}_{1}$ current;

3) To regulate the voltage of the common dc-link capacitor.

Fig.4 shows the control block diagram for the shunt VSC. The measured load current is transformed into the synchronous dq0 $\left(i_{l-d q 0}\right)$ reference frame by using

$$
\begin{gathered}
\left(\mathbf{i}_{1 \_\mathrm{dq} 0}=\mathbf{T}_{\mathrm{abc}}^{\mathrm{dq} 0} \mathbf{i}_{1 \_\mathrm{abc}}\right) \\
T_{a b c}^{d q o}=\frac{2}{3}\left[\begin{array}{ccc}
\cos (\omega t) & \cos \left(\omega t-120^{\circ}\right) & \cos \left(\omega t-120^{\circ}\right) \\
-\sin (\omega t) & -\sin \left(\omega t-120^{\circ}\right) & -\sin \left(\omega t-120^{\circ}\right) \\
\frac{1}{2} & \frac{1}{2} & \frac{1}{2}
\end{array}\right]
\end{gathered}
$$

Where the transformation matrix is shown in eq (2), at the bottom of the page. By this transform, the fundamental positive-sequence component, which is transformed into dc quantities in the $\mathrm{d}$ and $\mathrm{q}$ axes, can be easily extracted by low-pass filters (LPFs). Also, all harmonic components are transformed into ac quantities with a fundamental frequency shift.

$$
\begin{array}{ll}
i_{l_{-} d}=\bar{i}_{l_{-} d}+\tilde{l}_{l_{-} d} & \ldots . \\
i_{l_{-} q}=\bar{i}_{l_{-} q}+\tilde{l}_{l_{-} q} & \text {.... (3) }
\end{array}
$$

Where, $i_{l_{-} d}, i_{l_{-} q}$ are d-q components of load current, $\bar{i}_{l_{-} d}, \bar{i}_{l_{-} q}$ are dc components, and $\tilde{i}_{l_{-} d}, \tilde{i}_{l_{-} q}$ are the ac components of $i_{l_{-} d}, i_{l_{-} q}$.

If $i_{s}$ is the feeder current and $i_{p f}$ is the shunt VSC current and knowing $i_{s}=i_{l}-i_{p f}$, then $d-q$ components of the shunt VSC reference current are defined as follows:

$$
\begin{aligned}
& i_{p f_{-} d}^{r e f}=\tilde{l}_{l_{-} d} \\
& i_{p f_{-} q}^{r e f}=i_{l_{-} q}
\end{aligned}
$$


Consequently, the $\mathrm{d}-\mathrm{q}$ components of the feeder current are

$i_{s_{-} d}=i_{l_{-} q}$

$i_{s \_q}=0$

This means that there are no harmonic and reactive components in the feeder current. Switching losses cause the dc-link capacitor voltage to decrease. Other disturbances, such as the sudden variation of load, can also affect the dc link. In order to regulate the dc-link capacitor voltage, a proportional-integral (PI) controller is used as shown in Fig. The input of the PI controller is the error between the actual capacitor voltage $\mu_{\mathrm{dc}}$ and its reference value. The output of the PI controller (ie., $\Delta \mathrm{i}_{\mathrm{dc}}$ ) is added to the d component of the shunt-VSC reference current to form a new reference current as follows:

... (9) $\left\{\begin{array}{c}i_{p f_{-} d}^{r e f}=\tilde{l}_{l_{-} d}+\Delta i_{d c} \\ i_{p f_{-} q}^{r e f}=i_{l_{-} q}\end{array}\right.$

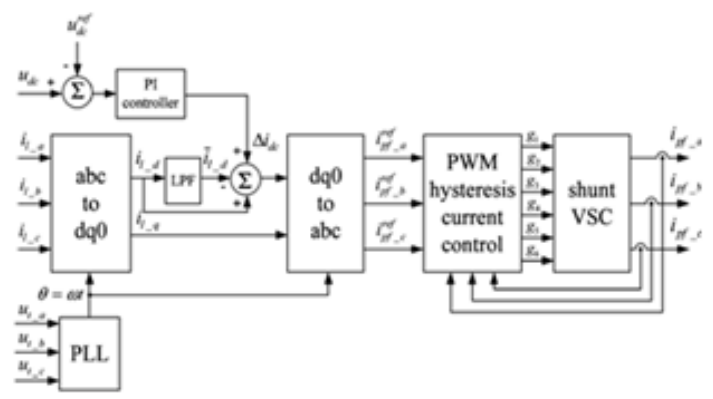

Fig.4. Control block diagram of shunt VSC

As shown in Fig.4, the reference current in eq (9) is then transformed back into the abc reference frame. By using PWM hysteresis current control, the output-compensating currents in each phase are obtained.

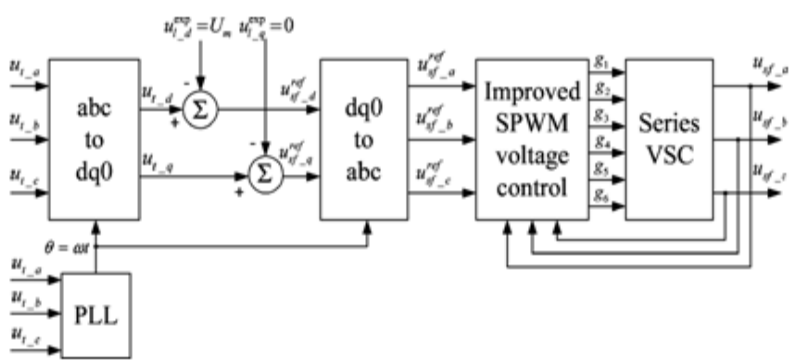

Fig 5 Control block diagram of series VSC

$\boldsymbol{i}_{p f_{-} a b c}^{r e f}=\boldsymbol{T}_{d q o}^{a b c} ; i_{p f_{-} a b c}^{r e f} ;\left(\boldsymbol{T}_{d q o}^{a b c}=\boldsymbol{T}_{d q o}^{a b c^{-1}}\right) \quad \ldots(\mathbf{1 0})$

Series-VSC: Functions of the series VSCs in each feeder are

1) To mitigate voltage sag and swell;

2) To compensate for voltage distortions, such as harmonics;

3) To compensate for interruptions (in Feeder2 only).

The control block diagram of each series VSC is shown in Fig. The bus voltage $\left(\mathrm{u}_{\mathrm{t}-\mathrm{abc}}\right)$ is detected and then transformed into the synchronous $\mathrm{dq}_{0}$ reference frame using

$u_{t d q 0}=T_{a b c}^{d q o} u_{t a b c}=u_{t i p}+u_{t i n}+u_{t 10}+u_{t h}$ 
Where,

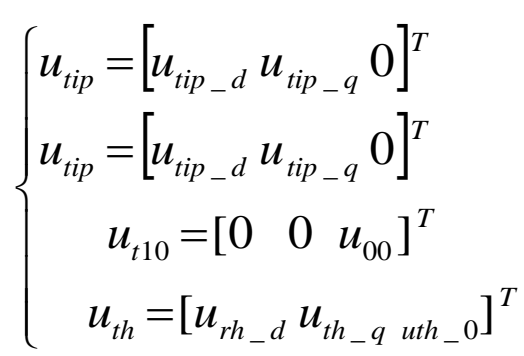

According to control objectives of the MC-UPQC, the load voltage should be kept sinusoidal with constant amplitude even if the bus voltage is disturbed. Therefore, the expected load voltage in the synchronous dq0 reference frame only $u_{l_{-} d q 0}^{\text {exp }}$ has one value.

$\boldsymbol{u}_{l_{-} d q 0}^{\exp }=\boldsymbol{T}_{a b c}^{d q 0} \boldsymbol{u}_{l_{-} a b c}^{\exp }=\left[\begin{array}{c}\boldsymbol{u}_{m} \\ 0 \\ 0\end{array}\right]$

Where the load voltage in the abc reference frame is $\boldsymbol{u}_{a b c}^{\exp }$

$u_{\text {labc }}^{\exp }=\left[\begin{array}{c}u_{m} \cos (\omega t) \\ u_{m} \cos \left(\omega t-120^{\circ}\right) \\ u_{m} \cos \left(\omega t+120^{\circ}\right)\end{array}\right]$

The compensating reference voltage in the synchronous dq0 reference frame $\boldsymbol{u}_{s f_{-} d q 0}^{\text {exp }}$ is defined as

$\boldsymbol{u}_{s f_{-} d q 0}^{r e f}=u_{t_{-} d q 0}-\boldsymbol{u}_{l_{-} d q 0}^{\exp }$

The compensating reference voltage is then transformed back into the abc reference frame. By using an improved SPWM voltage control technique the output compensation voltage of the series VSC can be obtained.

\section{Power-Rating Analysis Of The Mc-Upqc}

The power rating of the MC-UPQC is an important factor in terms of cost. Before calculation of the power rating of each VSC in the MC UPQC structure, two models of a UPQC are analyzed and the best model which requires the minimum power rating is considered. All voltage and current phasors used in this section are phase quantities at the fundamental frequency. There are two models for a UPQC - quadrature compensation (UPQC-Q) and in phase compensation (UPQC-P). In the quadrature compensation scheme, the injected voltage by the series- VSC maintains a quadrature advance relationship with the supply current so that no real power is consumed by the series VSC at steady state. This is a significant advantage when UPQC mitigates sag conditions. The series VSC also shares the volt ampere reactive (VAR) of the load along with the shunt-VSC, reducing the power rating of the shunt-VSC.

Fig. shows the phasor diagram of this scheme under a typical load power factor condition with and without a voltage sag.

When the bus voltage is at the desired value $\left(\mathrm{U}_{1}=\mathrm{U}_{\mathrm{t}}=\mathrm{U}_{0}\right)$, the series-injected voltage $\left(\mathrm{U}_{\mathrm{sf}}\right)$ is zero Fig. (a).

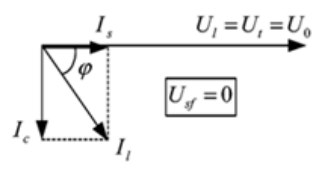

(a)

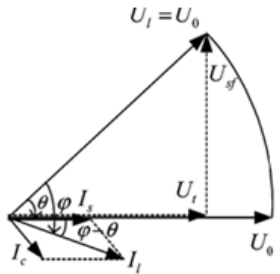

(b)

Fig 6 Phasor diagram of quadrature compensation a) Without voltage sag (b) With voltage sag. 
The shunt VSC injects the reactive component of loads current $\mathrm{I}_{\mathrm{c}}$, resulting in unity input-power factor. Furthermore, the shunt VSC compensates for not only the reactive component, but also the harmonic components of the load current $I_{c}$. The phasor diagram of Fig.6. explains the operation of this scheme in case of voltage sag.

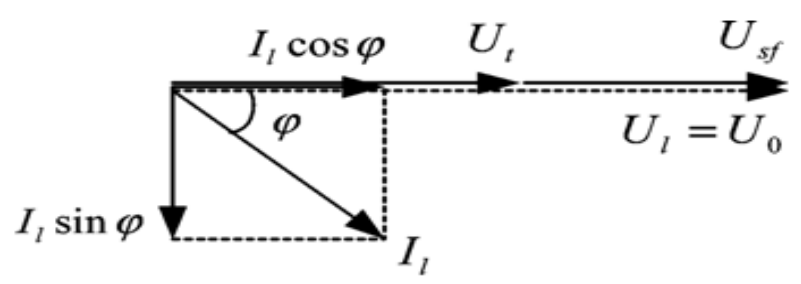

Fig.7. Phasor diagram of in phase compensation (supply voltage sag).

A comparison between in phase (UPQC-P) and quadrature (UPQC-Q) models is made for different sag conditions and load power factors. It is shown that the power rating of the shunt-VSC in the UPQC-Q model is lower than that of the UPQC-P, and the power rating of the series-VSC in the UPQC-P model is lower than that of the UPQC-Q for a power factor of less than or equal to 0.9. Also, it is shown that the total power rating of UPQC-Q is lower than that of UPQC-P where the VAR demand of the load is high.

As discussed in Section II, the power needed for interruption compensation in Feeder $_{2}$ must be supplied through the shunt VSC in Feeder1 and the series VSC in Feeder ${ }_{2}$. This implies that power ratings of these VSCs are

Greater than that of the series one in Feeder1. If quadrature compensation in Feeder ${ }_{1}$ and in phase compensation in Feeder 2 is selected, then the power rating of the shunt VSC and the series VSC (in Feeder ${ }_{2}$ ) will be reduced. This is an important criterion for practical applications.

As shown in Figs.6 and 7, load voltages in both feeders are kept constant at $\mathrm{U}_{0}$ regardless of bus voltages variation, and the load currents in both feeders are assumed to be constant at their rated values (i.e., $\mathrm{I}_{01}$ and $\mathrm{I}_{02}$ respectively)

$$
\begin{gathered}
\mathrm{U}_{\mathrm{t} 1}=\mathrm{U}_{\mathrm{t} 2}=\mathrm{U}_{0} \\
\left\{\begin{array}{l}
I_{l 1}=I_{01} \\
I_{l 2}=I_{02}
\end{array}\right.
\end{gathered}
$$

The load power factors in Feeder ${ }_{1}$ and Feeder 2 are assumed to be $\cos \varphi_{1}$ and $\cos \varphi_{2}$ and the per-unit sags, which must be compensated in Feeder ${ }_{1}$ and Feeder 2 , are supposed to be $\mathrm{x}_{1}$ and $\mathrm{x}_{2}$, respectively.

$$
i l_{-} d q o=T_{a b c}^{d q o} i_{L_{-} a b c+}
$$

If the MC-UPQC is lossless, the active power demand supplied by Feeder ${ }_{1}$ consists of two parts:

1) The active power demand of load in Feeder . $_{1}$

2) The active power demand for sag and interruption compensation in Feeder $_{2}$.

Thus, Feeder ${ }_{1}$ current $\mathrm{I}_{\mathrm{s} 1}$ can be found as

From Fig., the voltage injected by the series VSC in Feeder ${ }_{1}$ and thus the power rating of this converter $\left(\mathrm{S}_{\mathrm{vsc}}\right)$ can be calculated as

$\mathrm{U}_{\mathrm{sf} 1}=\mathrm{U}_{\mathrm{t} 1} \tan \theta=\mathrm{U}_{0}\left(1-\mathrm{x}_{1}\right) \tan \theta$

The shunt VSC current is divided into two parts:

1) The first part (i.e., $I_{\mathrm{cl}}$ ) compensates for the reactive component (and harmonic components) of Feeder 1 current and can be calculated from Fig. 4.6. As

$$
\begin{aligned}
& I_{c 1}=\sqrt{I_{l 1}^{2}+I_{s 1}^{2}-2 I_{l 1} I_{s 1} \cos (\varphi-\theta)} \\
& I_{c 1}=\sqrt{I_{01}^{2}+I_{s 1}^{2}-2 I_{01} I_{s 1} \cos \left(\varphi_{1}-\theta\right)}
\end{aligned}
$$


Where $I_{s 1}$ is calculated. This part of the shunt VSC current only exchanges reactive power (Q) with the system.

2) The second part provides the real power $(\mathrm{P})$, which is needed for sag or interruption compensation in Feeder 2 . Therefore, the power rating of the shunt VSC can be calculated as

$$
\begin{aligned}
& S_{V S C 2}=3 U_{l 1} I_{p f}=\sqrt[3]{Q^{2}+P^{2}} \\
& =\sqrt[3]{\left(U_{l 1} I_{c 1}\right)^{2}+\left(U_{s f 2} I_{l 2} \cos \varphi_{2}\right)^{2}} \\
& =3 U_{0} \sqrt{I_{c 1}^{2}+\left(x_{2} I_{02} \cos \varphi_{2}\right)^{2}} \ldots
\end{aligned}
$$

Where $I_{c 1}$ is calculated. Finally, the power rating of the series-VSC in Feeder ${ }_{2}$ can be calculated. For the worst-case scenario (i.e., interruption compensation), one must consider $\mathrm{x}_{2}=1$ Therefore,

$$
S_{V S C 3}=3 U_{s f 2} I_{l 2}=3 x_{2} U_{0} I_{02}
$$

IV. Matlab Design Of Mc-Upqc Study And Results

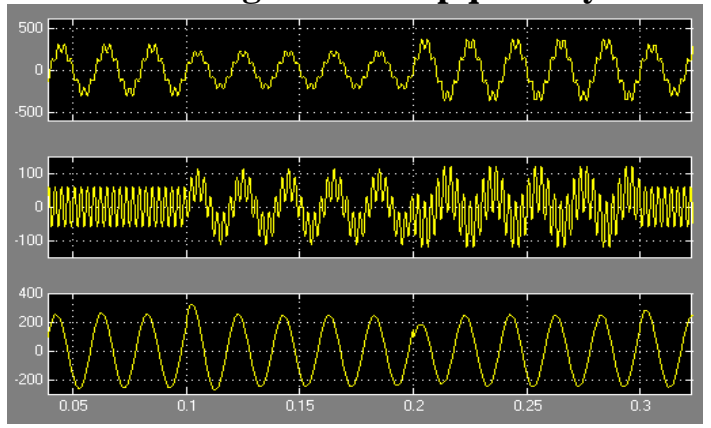

BUS $_{1}$ voltage, series compensating voltage, and load voltage in Feeder .

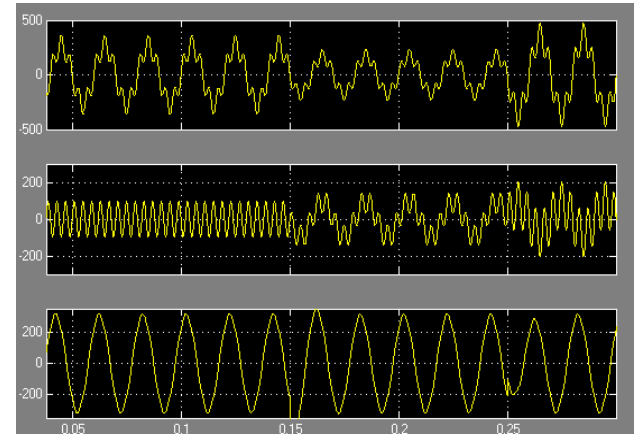

$\mathrm{BUS}_{2}$ voltage, series compensating voltage, and load voltage in Feeder ${ }_{2}$.

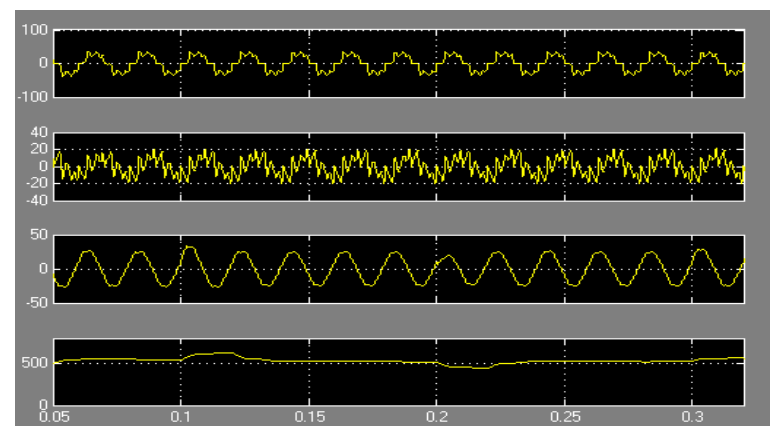

Nonlinear load current, compensating current, Feeder ${ }_{1}$ current, and capacitor voltage. 


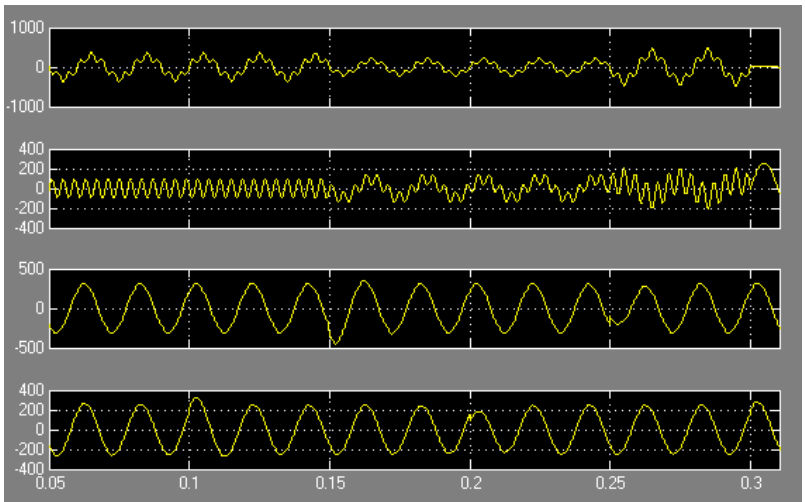

Simulation results for an upstream fault on Feeder ${ }_{2}: \mathbf{B U S}_{2}$ voltage, compensating voltage, and loads $\mathbf{L}_{1}$ and $L_{2}$ voltages.

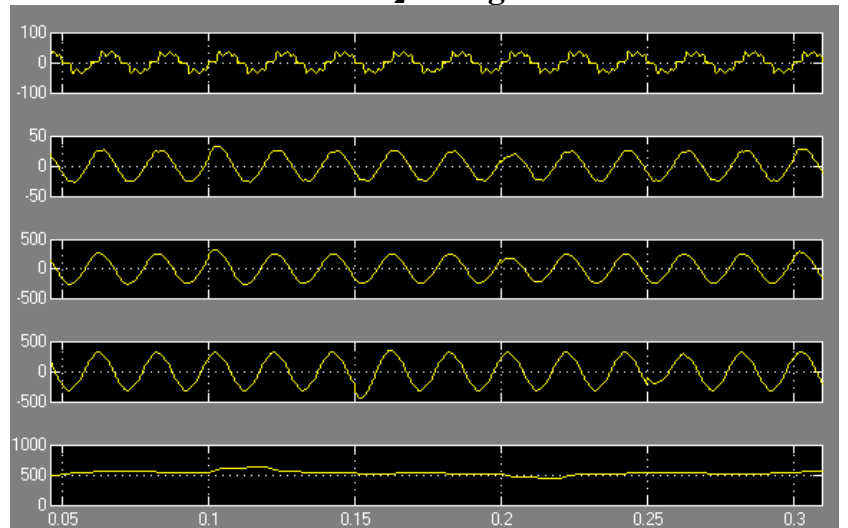

Simulation results for load change: nonlinear load current, Feeder $r_{1}$ current, load $L_{1}$ voltage, load $L_{2}$ voltage, and dc-link capacitor voltage.

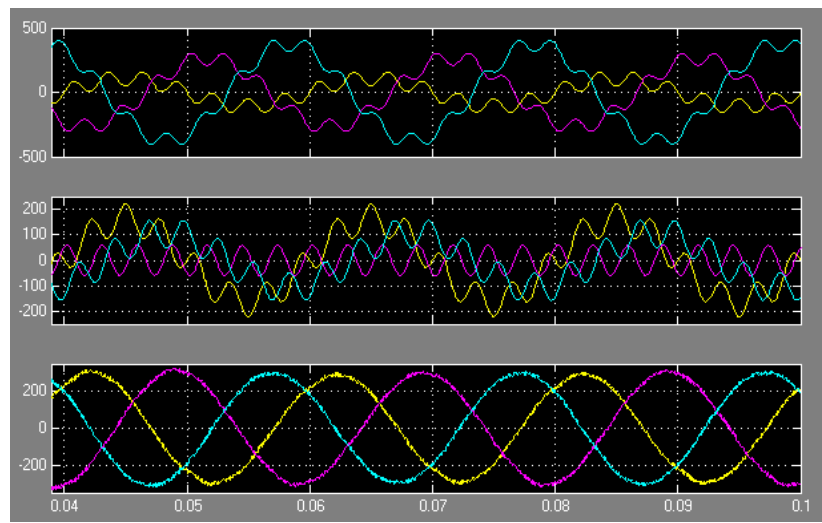

BUS $_{1}$ voltage, series compensating voltage, and load voltage in Feeder ${ }_{1}$ under unbalanced source voltage.

\section{Conclusion}

In this paper, a new configuration for simultaneous compensation of voltage and current in adjacent feeders has been proposed. The new configuration is named multi-converter unified power-quality conditioner (MC-UPQC). Compared to a conventional UPQC, the proposed topology is capable of fully protecting critical and sensitive loads against distortions, sags/swell, and interruption in two-feeder systems. The idea can be theoretically extended to multibus / multifeeder systems by adding more series VSCs. The performance of the MC-UPQC is evaluated under various disturbance conditions and it is shown that the proposed MC-UPQC offers the following advantages:

1) Power transfer between two adjacent feeders for sag/swell and interruption compensation;

2) Compensation for interruptions without the need for a battery storage system.

3) Sharing power compensation capabilities between two adjacent feeders which are not connected. 


\section{References}

[1] D. D. Sabin and A. Sundaram, "Quality enhances reliability," IEEE Spectr., vol. 33, no. 2, pp. 34-41, Feb. 1996

[2] M. Rastogi, R. Naik, and N. Mohan, "A comparative evaluation of harmonic reduction techniques in three-phase utility interface of power electronic loads," IEEE Trans. Ind. Appl., vol. 30, no. 5, pp. 1149-1155, Sep./Oct. 1994.

[3] F. Z. Peng, "Application issues of active power filters," IEEE Ind. Appl. Mag., vol. 4, no. 5, pp. 21-30, Sep../Oct. 1998.

[4] H. Akagi, "New trends in active filters for power conditioning," IEEE Trans. Ind. Appl., vol. 32, no. 6, pp. 1312-1322, Nov./Dec. 1996.

[5] L. Gyugyi, C. D. Schauder, S. L. Williams, T. R. Rietman, D. R. Torjerson, and A. Edris, "The unified power flow controller: A new approach to power transmission control,” IEEE Trans. Power Del., vol. 10, no. 2, pp. 1085-1097, Apr. 1995. 